\title{
ANALISIS TANAH UNTUK REKOMENDASI PEMUPUKAN PADA BUDIDAYA JAGUNG, PADI DAN KETELA POHON
}

\author{
Bagus Sri Mulyanto' $^{\text {(), }}$, Supriyadi' ${ }^{2)}$ dan Djoko Purnomo ${ }^{2)}$ \\ ${ }^{1)}$ Mahasiswa Program Studi Agroteknologi Fakultas Pertanian UNS \\ ${ }^{2)}$ Program Studi Agroteknologi Fakultas Pertanian UNS \\ Email: djpuruns@gmail.com
}

\begin{abstract}
The application of fertilization and giving organic matter of different causes differences in soil fertility status, with the availability of macro nutrients on a farm, then to know the action proper fertilization. The purpose of this study is to determine the dose fertilization fertility status of the local potential. The research was conducted using a survey method, ie by observing and sampling the soil directly in the field, followed by laboratory analysis to determine the chemical content of the soil. The results showed the level of soil fertility in Wonogiri low fertilizer needs are different in each district in Wonogiri. Areas with low nutrient availability will provide a high dose of fertilizer, and conversely a low fertilization results indicate the availability of nutrient elements in the soil are sufficient for plant growth, although it should still be nurtured to backup next season.
\end{abstract}

\section{Keywords: Dose Nutrients, Fertility, Fertilization, Fertilizers}

\section{PENDAHULUAN}

Pembangunan pertanian di Kabupaten Wonogiri meliputi bidang tanaman pangan, perkebunan, peternakan, perikanan, dan kehutanan. Diantara kelima bidang tersebut, potensi pertanian tanaman pangan paling besar, karena memberikan kontribusi yang besar terhadap pendapatan daerah. Kontribusi tanaman pangan terhadap pendapatan daerah yang cukup besar antara lain berasal dari padi, jagung, kacang tanah, kedelai, ketela pohon, dan ketela rambat tampak pada taraf produktivitas dan luas tanam (Wonogiri dalam Angka 2011). Potensi produksi tanaman tersebut masih dapat ditingkatkan melalui efisiensi pemupukan. Efisiensi rendah pemupukan dapat terjadi karena jenis dan sifat pupuk, waktu, syarat, metode pemupukan tidak tepat (AAK 2006), dan keperluan tanaman (Sutoro 2007), serta status hara tidak sinkron dengan kebutuhan tanaman (Balai Penelitian Tanah 2008).

Status hara tanah yang tidak diketahui berakibat pada jumlah pupuk untuk tanaman dapat berlebih atau kurang dari keperluan. Sebagai contoh, penggunaan pupuk $\mathrm{N}$ yang berlebih, $\mathrm{N}$ tidak termanfaatkan secara optimum (sebagian tercuci atau menguap) (Nugroho et al. 2009) sehingga memperbesar biaya produksi selain berpotensi merusak lingkungan akibat emisi gas $\mathrm{N}_{2} \mathrm{O}$ pada proses amonifikasi, nitrifikasi, dan denitrifikasi (Wahid et al. 2003). Dibanding antara tahun
1980 sampai 2000 yang penentuan dosis pupuk setiap komoditas berlaku secara nasional atau regional, saat ini sudah mengalami kemajuan dengan pengamatan warna daun seperti hasil penelitian Syafruddin et al. (2006), namun metode tersebut masih terbatas pada unsur $\mathrm{N}$. Teknologi penentuan keperluan pupuk tanaman dapat dilakukan melalui analisis laboratorium tentang sifat kimia tanah dan tanaman. Penggunaan metode tersebut bahkan dapat merancang kuantitas dan kualitas produksi tanaman yang dikehendaki (Dierolf et al. 2001). Disamping itu metode di atas juga dapat digunakan untuk memilih tanaman yang sesuai dengan kondisi lahan pertanian.

Saat ini basis data (data base) potensi atau kondisi ketersediaan unsur hara lahan pertanian setiap wilayah (desa dan kelurahan) di kecamatan se Kabupaten Wonogiri belum tersedia. Penelitian ini bertujuan mendeteksi karakter kimia tanah, jumlah serapan hara (Dierolf et al. 2001), dan hara terbawa panen (Dierolf et al. 2001) beberapa desa di Kabupaten Wonogiri untuk menghitung dosis pupuk yang diperlukan bagi tanaman padi unggul dan lokal, jagung unggul dan lokal, serta ketela pohon. Perhitungan yang cermat berdasar data yang sahih menghasilkan jumlah pupuk yang tepat sehingga efisiensi pemupukan tinggi. 


\section{METODE PENELITIAN}

Penelitian menggunakan metode survey pada tanah di suatu wilayah, petani, dan dinas pemerintahan. Lokasi penelitian di wilayah Kabupaten Wonogiri dengan posisi geografi antara $7^{\circ} 32^{\prime}$ Lintang Selatan (LS) dan $110^{\circ} 41^{\prime}$ Bujur Timur (BT) dengan antara $8^{\circ} 15^{\prime} \mathrm{LS}$ dan $111^{\circ} 18^{\prime}$ BT. Pelaksanaan survey antara bulan September 2012 hingga Januari 2013 yang bertepatan dengan musim penghujan. Pengamatan tanah dengan pengambilan sampel di lapangan, dilanjutkan dengan analisis laboratorium. Data pengamatan lain (wawancara, peta, dan buku statistiks) dianalisis secara deskriptif kualitatif (tidak terukur secara numerik) dan kuantitatif (terukur secara numerik). Analisis karakter tanah di Laboratorium Kimia dan Kesuburan Tanah, Fakultas Pertanian, Universitas Sebelas Maret, Surakarta, adalah: $\mathrm{pH}$ (dengan $\mathrm{pH}$ meter Elektrometrik), bahan organik, N-total (metode Kjeldahl), P total (metode Bray 1), K tertukar (metode Ekstrak amonium asetat ), $\mathrm{Ca}$ (metode SSA), Mg (metode SSA), S (metode SSA), KPK (metode Amonium asetat $\mathrm{pH} 7$ ), dan KB (metode Ekstrak ammonium asetat) . Perhitungan keperluan dosis pupuk untuk tanaman pangan (padi, jagung, dan ketela pohon) berdasarkan kandungan hara tanah, serapan hara tanaman, dan jumlah unsur hara yang terbawa panen. Tapak (site) pengambilan sampel tanah ditentukan secara purposif (purposive sampling). Ini dilakukan sesuai dengan tujuan penelitian dan keragaman karakter populasi. Sampel tanah jenis: Litosol (Entisol) dari Slogohimo, Nguntoronadi, Giriwoyo, Pracimantoro, dan Manyaran; Latosol (Ultisol) dari Jatisrono, Ngadirojo, dan Karangtengah; Mediteran (Alfisol) dari Giriwoyo, Wuryantoro, dan Purwantoro; Grumosol (Vertisol) dari Selogiri dan Kismantoro; Regosol (Inceptisol) dari Wuryantoro; Andosol (Andisol) dari Jatipurno; dan Alluvial (Entisol) dari Baturetno.

\section{HASIL DAN PEMBAHASAN}

Karakter tanah utama untuk menghitung dosis pupuk yang diperlukan bagi suatu tanaman adalah sifat kimia tanah karena kandungan unsur hara diketahui secara kuantitatif. Tingkat kesuburan tanah di Kabupaten Wonogiri dengan jenis tanah Litosol, Latosol, Mediteran, Grumosol, Regosol, Andosol, dan Alluvial berharkat rendah. Tanah Litosol yang terdapat di lima kecamatan mengandung $\mathrm{N}, \mathrm{P}, \mathrm{K}$, dan $\mathrm{S}$ sangat rendah, $\mathrm{Ca}$ rendah, serta $\mathrm{Mg}$ rendah hingga tinggi. Tanah Latosol yang meliputi tiga kecamatan kandungan unsur seperti pada tanah Litosol, hanya $\mathrm{Mg}$ yang mencapai harkat rendah hingga sedang, yang lain berharkat sangat rendah (untuk $\mathrm{K}$ ) hingga rendah. Demikian pula pada Mediteran, hanya Ca yang berharkat sedang dan $\mathrm{Mg}$ yang mencapai sedang hingga tinggi sedangkan yang lain sangat rendah hingga rendah. Pada tanah Grumosol hanya $\mathrm{Mg}$ yang berharkat sedang hingga tinggi, sedang yang lain berharkat sangat rendah hingga rendah. Hal hampir sama pada tanah Regosol, Andosol, dan Alluvial yang hanya $\mathrm{Mg}$ berharkat tinggi (Regosol) dan sedang (Andosol dan Alluvial) dan unsur hara yang lain berharkat sangat rendah hingga rendah (tabel 1). Secara umum kesuburan tanah rendah oleh karena kehilangan hara melalui hasil panen tanaman, aliran air permukaan (run off), dan pelindian (leaching) yang sangat dipengaruhi oleh unsur-unsur iklim, yaitu hujan, suhu dan kelembaban. Dapat ditambahkan bahwa topografi Kabupaten Wonogiri tidak rata, perbedaan antara satu kawasan dengan kawasan lain berakibat pada perbedaan sumber daya alam selain hampir sebagian besar lahan berbatu dan kering. Tanah terdiri atas dua tipe (Lange 1991) yaitu Climate Soil tipe, adalah tipe tanah yang selama pembentukan dipengaruhi oleh hujan dan temperatur $(\mathrm{R}=$ $\mathrm{r} / \mathrm{t}$, faktor hujan $\mathrm{R}=40$ ). Untuk daerah kering dengan $\mathrm{R}$ dibawah 40, tanaman tumbuh kurang baik karena pembentukan zat organik rendah. Sebaliknya bila R lebih dari 40 kemungkinan produksi zat organik akan lebih besar, sedangkan saat $\mathrm{R}=120$ tanah tersebut optimal bagi pertumbuhan. Aclimate Soil type, adalah tanah yang terbentuk dengan dominasi karakter batuan, namun demikian faktor iklim terutama hujan juga berperan penting. Air hujan mengikis top soil tanah yang merupakan bagian subur sehingga bila bagian ini terkikis terus menerus dan akhirnya hilang, maka tampak lapisan bagian bawah (sub soil) yang relatif kurang subur. Taraf kesuburan di atas ditunjang nilai kapasitas tukar kation (KTK), kandungan bahan organik (B), dan $\mathrm{pH}$ tanah (data tidak disajikan) yang rendah. Kondisi tanah termasuk masam berhubungan dengan presipitasi sehingga proses pelindian hara relatif cepat berakibat 
pH tanah meningkat (Sutedjo 2005). Berdasarkan kandungan hara tanah, serapan hara, dan hara yang mungkin terbawa hasil panen, diperoleh rekomendasi tambahan hara yang diperlukan pada budidaya Jagung hibrida dan lokal (tabel 2), Padi Ungul dan Lokal (tabel 3), dan Ketela Pohon (tabel 4).

Tabel 1. Kandungan hara dan harkat kesuburan tanah

\begin{tabular}{|c|c|c|c|c|c|c|c|}
\hline \multirow[b]{2}{*}{ No. } & \multirow{2}{*}{$\begin{array}{l}\text { Jenis } \\
\text { tanah }\end{array}$} & \multicolumn{6}{|c|}{ Kandungan hara } \\
\hline & & $\begin{array}{c}\mathrm{N} \\
(\%)\end{array}$ & $\begin{array}{c}\mathrm{P} \\
(\mathrm{ppm})\end{array}$ & $\begin{array}{c}\mathrm{K} \\
(\mathrm{me} \%)\end{array}$ & $\begin{array}{c}\mathrm{Ca} \\
(\mathrm{me} \%)\end{array}$ & $\begin{array}{c}\mathrm{Mg} \\
\text { (me \%) }\end{array}$ & $\begin{array}{c}\mathrm{S} \\
(\%)\end{array}$ \\
\hline 1. & litosol & $\begin{array}{l}0,04-0,05 \\
\quad(\mathrm{sr})\end{array}$ & $\begin{array}{c}5,94-8,58 \\
(\mathrm{sr})\end{array}$ & $\begin{array}{c}0,14-0,26 \\
\quad(\mathrm{sr})\end{array}$ & $\begin{array}{c}2,31-4,11 \\
\text { (r) }\end{array}$ & $\begin{array}{c}0,54-4,86 \\
(r-t)\end{array}$ & $\begin{array}{c}0,006-0,012 \\
\text { (sr) }\end{array}$ \\
\hline 2. & latosol & $\begin{array}{c}0,13-0,14 \\
\text { (r) }\end{array}$ & $\begin{array}{c}7,64-7,84 \\
\text { (r) }\end{array}$ & $\begin{array}{c}0,34-0,37 \\
\quad(\text { sr-r) }\end{array}$ & $\begin{array}{c}3,34-4,70 \\
\text { (r) }\end{array}$ & $\begin{array}{c}0,99-2,60 \\
(r-s)\end{array}$ & $\begin{array}{c}0,004-0,008 \\
\text { (r) }\end{array}$ \\
\hline 3. & $\begin{array}{l}\text { meditera } \\
\mathrm{n}\end{array}$ & $\begin{array}{l}0,02-0,10 \\
\quad(\mathrm{sr})\end{array}$ & $\begin{array}{c}7,89-8,65 \\
\quad(\mathrm{sr})\end{array}$ & $\begin{array}{c}0,15-0,32 \\
\quad(\text { sr-r) }\end{array}$ & $\begin{array}{l}6,25-7,60 \\
\text { (s) }\end{array}$ & $\begin{array}{c}2,23-4,58 \\
(\mathrm{~s}-\mathrm{t})\end{array}$ & $\begin{array}{c}0,006-0,007 \\
\text { (sr) }\end{array}$ \\
\hline 4. & grumosol & $\begin{array}{c}0,04-0,15 \\
\quad(s r-r)\end{array}$ & $\begin{array}{c}7,13-7,84 \\
(\mathrm{sr})\end{array}$ & $\begin{array}{c}0,13-0,19 \\
\quad(\mathrm{sr})\end{array}$ & $\begin{array}{c}0,31-2,31 \\
\quad(\mathrm{sr}-\mathrm{r})\end{array}$ & $\begin{array}{c}1,34-3,72 \\
(s-t)\end{array}$ & $\begin{array}{c}0,011 \\
(\mathrm{sr})\end{array}$ \\
\hline 5. & regosol & $\begin{array}{c}0,05 \\
(\mathrm{sr})\end{array}$ & $\begin{array}{c}8,65 \\
(\mathrm{sr})\end{array}$ & $\begin{array}{c}0,14 \\
(\mathrm{sr})\end{array}$ & $\begin{array}{c}6,78 \\
(\mathrm{~s})\end{array}$ & $\begin{array}{c}3,70 \\
(\mathrm{t})\end{array}$ & $\begin{array}{c}0,007 \\
(\mathrm{sr})\end{array}$ \\
\hline 6. & andosol & $\begin{array}{c}0,15 \\
(\mathrm{r})\end{array}$ & $\begin{array}{l}6,91 \\
(\mathrm{sr})\end{array}$ & $\begin{array}{c}0,39 \\
\text { (r) }\end{array}$ & $\begin{array}{c}4,70 \\
(\mathrm{r})\end{array}$ & $\begin{array}{c}2,29 \\
(\mathrm{~s})\end{array}$ & $\begin{array}{c}0,008 \\
(\mathrm{sr})\end{array}$ \\
\hline 7. & alluvial & $\begin{array}{c}0,06 \\
(\mathrm{sr})\end{array}$ & $\begin{array}{l}8,12 \\
(\mathrm{sr})\end{array}$ & $\begin{array}{c}0,13 \\
(\mathrm{sr})\end{array}$ & $\begin{array}{c}0,33 \\
(\mathrm{sr})\end{array}$ & $\begin{array}{c}2,10 \\
(\mathrm{~s})\end{array}$ & $\begin{array}{c}0,013 \\
(\mathrm{sr})\end{array}$ \\
\hline
\end{tabular}

Keterangan: Kandungan hara tanah dan harkat kesuburan menurut Blakemore et al. (1987). Harkat kesuburan, sr: sangat rendah; r: rendah; s: sedang; t: tinggi; N: Nitrogen, P: fosfat, K: kalium, Ca: kalsium, Mg: magnesium, S: sulfur.

Tabel 2. Tambahan hara untuk tanaman jagung hibrida dan lokal

\begin{tabular}{|c|c|c|c|c|c|c|c|c|}
\hline \multirow{2}{*}{ No. } & \multirow{2}{*}{ Jenis tanah } & \multirow{2}{*}{ Jagung } & \multicolumn{6}{|c|}{ Tambahan hara yang diperlukan (kg/ha) } \\
\hline & & & $\mathrm{N}$ & $\mathrm{P}$ & K & $\mathrm{Ca}$ & $\mathrm{Mg}$ & $\mathrm{S}$ \\
\hline \multirow{2}{*}{1.} & \multirow{2}{*}{ litosol } & Hibrida & $120,8-126,8$ & $22,5-22,6$ & $72,6-75,2$ & $6,4-7,9$ & $13,8-16,4$ & $12,2-12,5$ \\
\hline & & Lokal & $71,3-77,2$ & $13,4-13,6$ & $39,8-42,1$ & $2,4-3,9$ & $6,7-9,2$ & $3,7-4,3$ \\
\hline \multirow{2}{*}{2.} & \multirow{2}{*}{ latosol } & Hibrida & $105,8-122,8$ & $22,6-22,6$ & $143,6-143,9$ & $6,2-7,4$ & $15,4-16,2$ & $12,5-12,9$ \\
\hline & & Lokal & $56,2-65,6$ & $13,4-13,5$ & $36,2-38,7$ & $2,2-3,4$ & $8,3-8,6$ & $4,0-4,5$ \\
\hline \multirow{2}{*}{3.} & \multirow{2}{*}{ mediteran } & Hibrida & $113,6-125,6$ & $143,4-143,6$ & $71,4-75,2$ & $4,3-5,1$ & $14,2-15,6$ & $12,6-12,7$ \\
\hline & & Lokal & $64,0-75,9$ & $13,4-13,5$ & $38,6-42,4$ & $0,3-1,1$ & $0,2-2,5$ & $4,1-4,2$ \\
\hline \multirow{2}{*}{4.} & \multirow{2}{*}{ grumosol } & Hibrida & $111,5-125,3$ & $22,5-22,6$ & $74,6-75,4$ & $7,9-9,2$ & $14,8-16,2$ & $12,2-12,3$ \\
\hline & & Lokal & $61,9-75,7$ & $13,4-13,5$ & $41,8-42,6$ & $3,9-5,2$ & $7,8-9,1$ & $3,7-3,8$ \\
\hline \multirow{2}{*}{5.} & \multirow{2}{*}{ regosol } & Hibrida & 123,46 & 268,4 & 75,6 & 4,2 & 15,0 & 12,6 \\
\hline & & Lokal & 73,86 & 13,4 & 42,8 & 0,2 & 7,9 & 4,1 \\
\hline \multirow{2}{*}{6.} & \multirow{2}{*}{ andosol } & Hibrida & 106,64 & 231,8 & 71,1 & 6,3 & 15,6 & 12,5 \\
\hline & & Lokal & 57,04 & 13,5 & 38,3 & 2,3 & 8,5 & 3,9 \\
\hline \multirow{2}{*}{7.} & \multirow{2}{*}{ alluvial } & Hibrida & 121,95 & 265,1 & 75,3 & 9,2 & 15,5 & 12,0 \\
\hline & & Lokal & 72,35 & 13,5 & 42,5 & 5,2 & 8,4 & 3,5 \\
\hline
\end{tabular}

Keterangan: Jagung hibrida dan lokal masing-masing untuk mencapai hasil hiji 4,5 dan 2,5 ton/ha. 
Tabel 3. Tambahan hara untuk tanaman padi unggul dan lokal

\begin{tabular}{|c|c|c|c|c|c|c|c|c|}
\hline \multirow[b]{2}{*}{ No. } & \multirow{2}{*}{$\begin{array}{l}\text { Jenis } \\
\text { tanah }\end{array}$} & \multirow{2}{*}{ Padi } & \multicolumn{6}{|c|}{ Tambahan hara yang diperlukan (kg/ha) } \\
\hline & & & $\mathrm{N}$ & $\mathrm{P}$ & $\mathrm{K}$ & $\mathrm{Ca}$ & $\mathrm{Mg}$ & $\mathrm{S}$ \\
\hline \multirow{2}{*}{1.} & \multirow{2}{*}{ litosol } & Unggul & $96,3-101,9$ & $15,4-15,5$ & $105,6-108,2$ & $8,3-9,8$ & $7,9-10,5$ & $3,7-4,3$ \\
\hline & & Lokal & $50,2-56,2$ & $9,1-9,2$ & $50,3-52,9$ & $3,5-4,9$ & $2,9-5,5$ & $1,4-1,9$ \\
\hline \multirow{2}{*}{2.} & \multirow{2}{*}{ latosol } & Unggul & $81,2-90,6$ & $15,4-15,5$ & $101,9-104,5$ & $8,1-9,3$ & $9,5-10,3$ & $4,0-4,5$ \\
\hline & & Lokal & $35,2-44,6$ & $9,1-9,2$ & $46,6-49,1$ & $3,3-4,5$ & $4,5-5,3$ & $1,7-2,2$ \\
\hline \multirow{2}{*}{3.} & \multirow{2}{*}{ mediteran } & Unggul & $89,1-100,9$ & $15,4-15,5$ & $1104,4-108,2$ & $6,2-7,0$ & $8,3-9,7$ & $4,1-4,2$ \\
\hline & & Lokal & $43,154,1$ & $9,1-9,2$ & $49,1-52,9$ & $1,4-2,2$ & $3,3-4,7$ & $1,8-1,9$ \\
\hline \multirow{2}{*}{4.} & \multirow{2}{*}{ grumosol } & Unggul & $86,9-100,7$ & $15,4-15,5$ & $107,5-108,4$ & $9,8-11,1$ & $8,9-10,3$ & $3,7-3,8$ \\
\hline & & Lokal & $40,9-54,7$ & $9,1-9,2$ & $52-53$ & $5,0-6,2$ & $3,9-5,2$ & $1,4-1,5$ \\
\hline \multirow{2}{*}{5.} & \multirow{2}{*}{ regosol } & Unggul & 98,9 & 15,4 & 108,6 & 6,1 & 9,1 & 4,1 \\
\hline & & Lokal & 52,7 & 9,1 & 53,3 & 1,3 & 4,1 & 1,8 \\
\hline \multirow{2}{*}{6.} & \multirow{2}{*}{ andosol } & Unggul & 82,0 & 15,5 & 104,1 & 8,2 & 9,7 & 3,9 \\
\hline & & Lokal & 36,0 & 9,2 & 48,7 & 7,5 & 4,7 & 1,7 \\
\hline \multirow{2}{*}{7.} & \multirow{2}{*}{ alluvial } & Unggul & 97,4 & 15,5 & 108,3 & 11,1 & 9,6 & 3,5 \\
\hline & & Lokal & $51,4,1$ & 9,1 & 53,0 & 13,9 & 4,5 & 1,2 \\
\hline
\end{tabular}

Keterangan: Padi Unggul dan lokal masing-masing untuk mencapai hasil biji 4 dan 2 ton/ha.

Tabel 4. Tambahan hara untuk tanaman ketela pohon

\begin{tabular}{|c|c|c|c|c|c|c|c|}
\hline \multirow{2}{*}{ No. } & \multirow{2}{*}{ Jenis tanah } & \multicolumn{6}{|c|}{ Tambahan hara yang diperlukan (kg/ha) } \\
\hline & & $\mathrm{N}$ & $\mathrm{P}$ & $\mathrm{K}$ & $\mathrm{Ca}$ & $\mathrm{Mg}$ & $\mathrm{S}$ \\
\hline 1. & litosol & $86,9-92,9$ & $17,5-17,6$ & $87,3-89,9$ & $47,4-48,8$ & $12,1-14,7$ & $9,1-9,7$ \\
\hline 2. & latosol & $71,9-81,3$ & $17,5-17,5$ & $83,6-86,1$ & $47,2-48,4$ & $13,7-14,5$ & $9,4-9,8$ \\
\hline 3. & mediteran & $79,8-91,7$ & $17,5-17,6$ & $186,1-89,8$ & $45,3-46,1$ & $12,5-$ & $9,5-9,6$ \\
\hline 4. & grumosol & $77,6-91,4$ & $17,5-17,6$ & $89,1-90,1$ & $48,9-50,17$ & $8,9-10,3$ & $9,1-9,2$ \\
\hline 5. & regosol & 89,5 & 17,5 & 90,3 & 45,1 & 9,1 & 9,5 \\
\hline 6. & andosol & 72,7 & 17,6 & 85,7 & 47,3 & 9,7 & 9,4 \\
\hline 7. & alluvial & 88,0 & 17,6 & 9,0 & 50,1 & 9,6 & 8,9 \\
\hline
\end{tabular}

Keterangan : Hasil Ketela Pohon untuk mencapai hasil umbi basah 20 ton/ha.

Hasil rata - rata pehitungan ulangan didapatkan rekomendasi pemupukan yang paling besar untuk pupuk $\mathrm{N}$, yaitu sebesar $126,76 \mathrm{Kg} / \mathrm{Ha}$, dan paling sedikit, yaitu sebesar 105,80 Kg/Ha. Dari hasil perhitungan kebutuhan pupuk $\mathrm{P}$ untuk tanaman jagung hibrida rata - rata $22 \mathrm{Kg} / \mathrm{Ha}$. Kebutuhan pupuk $\mathrm{Ca}$ pada tanaman jagung hibrida berbeda-beda berkisar antara $4-9 \mathrm{~kg} / \mathrm{ha}$, kebutuhan pupuk Mg pada tanaman jagung hibrida berbeda-beda berkisar antara $13-16 \mathrm{~kg} / \mathrm{ha}$ hal ini terjadi karena perbedaan komoditas yang ditaman petani dan kegiatan pemupukan yang dilakukan oleh petani memberikan status ketersediaan unsur hara yang berbeda dan akan memberikan hasil rekomendasi pemupukan yang berbeda pula. Untuk kebutuhan pupuk $S$ yang didasarkan pada kebutuhan unsur hara sulfur pada luas lahan perhektar maka didapatkan rekomendasi pupuk ZA dengan dosis diatas $12 \mathrm{~kg} \mathrm{ZA} / \mathrm{ha}$,

Hasil pehitungan kebutuhan pupuk didapatkan rekomendasi pemupukan yang paling besar untuk pupuk urea, yaitu sebesar $167,28 \mathrm{Kg} / \mathrm{Ha}$, Kebutuhan pupuk SP-36 untuk tanaman jagung lokal rata - rata $85 \mathrm{Kg} / \mathrm{Ha}$, Kebutuhan pupuk $\mathrm{K}$ berupa pupuk $\mathrm{KCl}$ pada tanaman jagung lokal secara umum bervariasi tetapi lebih dari $60 \mathrm{Kg} / \mathrm{ha}$, kebutuhan pupuk $\mathrm{Za}$ dengan rekomendasi pupuk ZA dengan dosis rata - rata diatas $30 \mathrm{~kg} \mathrm{ZA/ha.}$

Secara umum rekomendasi kebutuhan pupuk urea tanaman padi unggul berkisar antara $176-222 \mathrm{~kg} / \mathrm{ha}$. Kebutuhan pupuk SP36 untuk tanaman padi unggul rata - rata 98 $\mathrm{Kg} / \mathrm{Ha}$, tetapi pada Kecamatan Slogohimo memiliki kebutuhan pupuk $\mathrm{P}$ yang paling tinggi yaitu sebesar $15,55 \mathrm{Kg} / \mathrm{Ha}$, bila dikonversikan ke pupuk SP-36 sebesar 98,94 $\mathrm{kg} / \mathrm{ha}$. Kebutuhan pupuk K berupa pupuk $\mathrm{KCl}$ pada tanaman padi unggul secara umum lebih dari $100 \mathrm{Kg} / \mathrm{ha}$. Kebutuhan pupuk Dolomit pada tanaman padi unggul berbeda-beda berkisar antara 13 - $24 \mathrm{~kg} / \mathrm{ha}$. kebutuhan pupuk Za yang didasarkan pada kebutuhan unsur hara sulfur padfa luas lahan perhektar 
maka didapatkan rekomendasi pupuk ZA dengan dosis antara 14,76 - 18,58 kg ZA/ha. Rata pehitungan didapatkan rekomendasi pemupukan Padi lokal untuk pupuk urea, yaitu sebesar 122,09 Kg/Ha dan merupakan dosis pupuk tertinggi dari semua Kecamatan di Kabupaten Wonogiri. Dari hasil perhitungan kebutuhan pupuk SP-36 untuk tanaman padi lokal rata - rata $58 \mathrm{Kg} / \mathrm{Ha}$. Kebutuhan pupuk $\mathrm{K}$ berupa pupuk $\mathrm{KCl}$ pada tanaman padi lokal bebeda di tiap Kecamatan, namun secara rata rata diatas $80 \mathrm{Kg} / \mathrm{ha}$. Kebutuhan pupuk Dolomit pada tanaman padi lokal berbedabeda berkisar antara 2,84 - 13,95 kg/ha. Rekomendasi pupuk ZA dengan dosis yang bervariasi antara $5,18-9 \mathrm{~kg} / \mathrm{ha}$.

Hasil pehitungan kebutuhan pupuk didapatkan rekomendasi pemupukan pada tanaman ketela pohon yang paling besar untuk pupuk urea, yaitu sebesar $201 \mathrm{Kg} / \mathrm{Ha}$. Dari hasil perhitungan kebutuhan pupuk SP-36 untuk tanaman ketela pohon rata - rata 112 $\mathrm{Kg} / \mathrm{Ha}$. hasil kebutuhan pupuk $\mathrm{K}$ berupa pupuk $\mathrm{KCl}$ pada tanaman ketela pohon secara umum lebih dari $130 \mathrm{Kg} / \mathrm{ha}$. Kebutuhan pupuk Dolomit pada tanaman ketela pohon berbedabeda berkisar antara 100,40 - 111,50 kg/ha. kebutuhan pupuk Za yang didasarkan pada kebutuhan unsur hara sulfur pada luas lahan perhektar, pemberian pupuk ZA sebagai sumber hara $\mathrm{N}$ dan $\mathrm{S}$ pada takaran yang meningkat dari 50 sampai $100 \mathrm{~kg} / \mathrm{ha}$

\section{KESIMPULAN}

Kesimpulan yang dapat ditarik dari penelitian ini adalah : Jenis tanah Vertisol di 2 Kecamatan yaitu Selogiri dan Kismantoro, tanah Entisol di 7 Kecamatan yaitu Slogohimo, Nguntoronadi, Giriwoyo, Pracimantoro, Manyaran, Baturetno dan Wuryantoro, masing - masing jenis tanah tersebut mempunyai tingkat kesuburan sangat rendah sampai sedang. Tanah Ultisol di 3 Kecamatan yaitu Jatisrono, Ngadirojo, Karangtengah, tanah Andisol di Kecamatan Jatipurno, masing - masing jenis tanah tersebut mempunyai tingkat kesuburan rendah. Tanah Alfisol di 3 Kecamatan yaitu Giriwoyo, Wuryantoro, Purwantoro, mempunyai tingkat kesuburan rendah sampai sedang,

Kebutuhan pupuk untuk jagung hibrida antara lain : pupuk $\mathrm{N}$ berkisar 105,80 - 126,76 $\mathrm{Kg}$ N/Ha. kebutuhan pupuk $\mathrm{P}$ rata - rata 22 $\mathrm{Kg} / \mathrm{Ha}$. Kebutuhan pupuk $\mathrm{K}$ secara umum lebih dari $70 \mathrm{Kg} \mathrm{K} / \mathrm{ha}$. Kebutuhan untuk unsur
Ca berbeda-beda berkisar antara 4,18 - 9,18 $\mathrm{kg} / \mathrm{ha}$, untuk unsur $\mathrm{Mg}$ berbeda-beda berkisar antara $13,79-16,41 \mathrm{~kg} / \mathrm{ha}$, untuk unsur $\mathrm{S}$ rata - rata $12 \mathrm{Kg} / \mathrm{Ha}$. Kebutuhan pupuk untuk jagung lokal antara lain : pupuk $\mathrm{N}$ berkisar 56,20 - 76,95 Kg N/Ha. kebutuhan pupuk $\mathrm{P}$ rata - rata $13 \mathrm{Kg} / \mathrm{Ha}$. Kebutuhan pupuk K secara umum lebih dari $36 \mathrm{Kg} \mathrm{K} / \mathrm{ha}$. Kebutuhan untuk unsur $\mathrm{Ca}$ berbeda-beda berkisar antara $0,18-5,18 \mathrm{~kg} / \mathrm{ha}$, untuk unsur $\mathrm{Mg}$ berbeda-beda berkisar antara 6,69-9,31 $\mathrm{kg} / \mathrm{ha}$, untuk unsur $\mathrm{S}$ rata - rata $7 \mathrm{Kg} / \mathrm{Ha}$.

Kebutuhan pupuk untuk Padi Unggul antara lain : pupuk $\mathrm{N}$ berkisar 81,20 - 102,16 $\mathrm{Kg}$ N/Ha. kebutuhan pupuk $\mathrm{P}$ rata - rata 15 $\mathrm{Kg} / \mathrm{Ha}$. Kebutuhan pupuk $\mathrm{K}$ secara umum lebih dari $101 \mathrm{Kg} \mathrm{K} / \mathrm{ha}$. Kebutuhan untuk unsur $\mathrm{Ca}$ berbeda-beda berkisar antara 6,08 $11,08 \mathrm{~kg} / \mathrm{ha}$, untuk unsur $\mathrm{Mg}$ berbeda-beda berkisar antara $7,89-10,51 \mathrm{~kg} / \mathrm{ha}$, untuk unsur $\mathrm{S}$ rata - rata $4 \mathrm{Kg} / \mathrm{Ha}$. Kebutuhan pupuk untuk Padi Lokal antara lain : pupuk $\mathrm{N}$ berkisar 35,20 - 56,16 Kg N/Ha. kebutuhan pupuk $\mathrm{P}$ rata - rata $9 \mathrm{Kg} / \mathrm{Ha}$. Kebutuhan pupuk $\mathrm{K}$ secara umum lebih dari $46 \mathrm{Kg} \mathrm{K} / \mathrm{ha}$. Kebutuhan untuk unsur $\mathrm{Ca}$ berbeda-beda berkisar antara 1,28 - 6,28 kg/ha, untuk unsur $\mathrm{Mg}$ berbeda-beda berkisar antara 2,89 - 5,51 $\mathrm{kg} / \mathrm{ha}$, untuk unsur $\mathrm{S}$ rata - rata $1,5 \mathrm{Kg} / \mathrm{Ha}$.

Kebutuhan pupuk untuk Ketela Pohon antara lain : pupuk $\mathrm{N}$ berkisar 71,90 - 92,86 $\mathrm{Kg} \mathrm{N} / \mathrm{Ha}$. kebutuhan pupuk $\mathrm{P}$ rata - rata 17 $\mathrm{Kg} / \mathrm{Ha}$. Kebutuhan pupuk $\mathrm{K}$ secara umum lebih dari $90 \mathrm{Kg} \mathrm{K} / \mathrm{ha}$. Kebutuhan untuk unsur Ca berbeda-beda berkisar antara 45,18 - 50,18 $\mathrm{kg} / \mathrm{ha}$, untuk unsur $\mathrm{Mg}$ berbeda-beda berkisar antara $12,09-14,71 \mathrm{~kg} / \mathrm{ha}$, untuk unsur $\mathrm{S}$ rata - rata $9 \mathrm{Kg} / \mathrm{Ha}$.

\section{DAFTAR PUSTAKA}

Dierolf. T, T. Fairhurst, E. Mutert. 2001. Soil Fertility Kit: A tool Kit for Acid, Upland Soil Fertility Management in Southeast Asia. PT Jasa Katom; and Potash \& Phosphate Institute (PPI). Canada.

Hadrian. Siregar 1981. Budidaya Tanaman Padi di Indonesia. PT Sastro Hudaya. Jakarta.

IPNS. 2000. Pupuk dan Cara Pemupukan. Rineka Citra. Jakarta. London.

Lange, M. 1991. General Geology. Gaya Media Pratama : Jakarta 
Sutedjo dan Kartasapoetro.2005. Teknologi Konservasi Tanah Dan Air. Rineka Cipta.Jakarta.

Syafruddin, Saenong, dan Subandi. 2006. Penggunaan bagan warna daun (BWD) untuk efisiensi pemupukan $\mathrm{N}$ pada tanaman jagung. Penelitian Pertanian
Tanaman Pangan. Vol. 27 No. 1 2008.P.24.

Winarso, Sugeng. 2005. Kesuburan Tanah. Gava Media .Yoyakarta

Wonogiri Dalam Angka. 2011. Badan Pusat Statistik Wonogiri. 